\title{
$\mathbf{R}_{\text {EVIEW }}$
}

\author{
Sylwia Głuch
}

University of Warsaw, Poland

\section{The Digitalization of Public Diplomacy, Ilan Manor, Springer International Publishing, 2019}

Nowadays, it is difficult to find areas of life that have not been changed by the Internet, social media or modern communication technology. The most noticeable areas influenced by these phenomena are education, trade and tourism; however, politics is also such a field. Ilan Manor, a researcher at the University of Oxford, UK, took up a challenge of analyzing digital diplomacy in times of crisis. In his 2019 book The Digitalization of Public Diplomacy he discusses public diplomacy in the 21st century and its adaptation to positive and negative aspects of these times.

The book is divided into ten chapters. In the first chapter - "Introduction" the author presents an example of activities within digitalized public diplomacy, i.e. Iran negotiations on partially halting its nuclear program in exchange for having some of the economic sanctions against them lifted, which is known as the Iran Deal. Then the author discusses definitions of such key concepts as public diplomacy or new public diplomacy and goes on to present Melissen's definition of digital diplomacy as a "new" public diplomacy that focuses on engaging with members of digital societies while shifting from monologue towards dialogue, engagement and long-term relationship. On this ground, Manor draws a conclusion, considered the book's keynote, that digitalization (of public diplomacy) is a slow process in which the adoption of digital technologies challenges well-entrenched working routines and norms as well as acceptable risks and rewards; however, this process is not uniform for all Ministries of Foreign Affairs (MFAs). 
Next, the chapter presents the three main goals of the book: (1) to offer a new conceptual framework for understanding and researching the influence of digital technologies on public diplomacy; (2) to demonstrate that one cannot understand the digitalization of public diplomacy without first characterising the digital society; and (3) to diversify the structure of research on public diplomacy through examining the processes of public diplomacy digitalization in MFAs from different world regions. The author also emphasizes the fact that the book limits the scope of its analysis to activities of MFAs, embassies and diplomats and does not discuss such actors as NGOs, civil society organizations, and individuals. The introduction thus provides the readers with an opportunity to understand the basics of the research and the concept of public diplomacy.

According to the assumption that one cannot understand the digitalization of public diplomacy without first characterizing the digital society, the second chapter is fully devoted to the latter. This concept is discussed in the context of definitions of such terms as the network society, the information society, the sharing society, and the surveilled society. The author proves that the digitalization of public diplomacy has been shaped by the digital society and thus the two are related. This means that the digitalization of public diplomacy is influenced not only by a myriad of organizational and national factors but also by professional background of those in charge, availability of digital technologies, as well as norms and customs of a given society. For readers who are new to the field, this chapter serves as a roadmap since this profound theoretical foundation is helpful for future studies on digitalization of public diplomacy and fills up the gap in international research on this process.

The third chapter, similarly to all the following ones, can be easily divided into two parts. The first part gives a theoretical background helpful for scholars in their further research in this field. The chapter explains the origins of the concept that bloomed after 9/11 attacks and is now called the "new" public diplomacy. In the author's opinion, this experience led to the shift in public diplomacy from monologue to dialogue and initiated the long-term process of digitalization of public diplomacy. The second part of this chapter aims to support the presented assumptions with case studies, which include here Sweden's virtual embassy (to Second Life), online Q\&A with Israeli and Hamas officials, EU social media campaigns in Israel, and US framing activities on Twitter. All of them prove that digitalization of public diplomacy is a long process of listening, trying, building and engaging.

The fourth chapter, "From Targeting to Tailoring - Two Stages of Public Diplomacy's Digitalization", presents such case studies as Canada's consular diplomacy, the iBrand of the Russian embassy to London, Israel's algorithmic activities on social media, foreign policy narrative of Iranian leaders, and the "Know India" smartphone application developed by India's Ministry of External Affairs (MEA). The title of this chapter refers to Marcus Holmes (2015) and his idea that the process of digitalization of public diplomacy can be influenced by two types of change: bottom-up and top-down. The first one refers to a situation in which diplomats and embassies shape the process of adopting digital technologies by MFAs. The second type of change is caused by an external shock, such 
as the Crimean crisis, which modifies the ways in which MFAs attain their goals and public diplomacy is conducted. What made great impact at the beginning of the second stage of digitalization were the so-called digital natives (people born after 1980, who by 2014 had become low-rank officials at MFAs) and their digital proficiency. Among many other transitions, the author discusses the shifts from linear to algorithmic communication models, from digital tactics to digital strategies, from argument-based to narrative-based diplomacy and from targeted to tailored communication.

The fifth chapter is devoted to recent concepts such as filter bubbles, echo chambers and digital influence campaigns that maneuver between public diplomacy and propaganda. For the sake of clarity, the author provides precise definitions of these terms. Next, referring to arguments that social media sites are the undoing of democracy, he presents an interesting statement that these platforms have actually never been meant to be democratic (nor were they the first mass medium to be regarded as undemocratic). These digital platforms were designed to make a profit from advertisements tailored for digital publics by algorithms. It is algorithms that govern online experiences of the users, decide what virtual content is displayed, and gather as much information as possible to match the adverts to the user. As the author proves in this chapter, algorithms have been weaponized by some nations to spread fake news or even create social disorder. The two case studies presented in this chapter include UK Foreign and Commonwealth Office's blogosphere and Israel's new model of algorithmic diplomacy. These examples show how officials can fight using filter bubbles, echo chambers and online propaganda.

The sixth chapter asks whether the "new" public diplomacy is reality or fiction. The starting point here is an observation that after disinformation in social media intensified, diplomats became less willing to begin new engagements and maintain old relationships via digital platforms. To prove it, Manor introduces a new model for measuring the two-way communication and "dialogic engagement" between a diplomatic institution and digital publics based on the works of Bjola, Jiang and his own. Definitely, this serves as a powerful asset for future research. The chapter also presents interesting case studies, i.e. the activities of five African MFAs and four Lithuanian embassies. There are several analyses of public diplomacy in African countries, which adds to the value of this book.

As its title suggests, the chapter "Overcoming the Limitations of Traditional Diplomacy" gives the readers an overview on the transition from diplomacy conducted in a traditional way into diplomacy undergoing the digitalization process. Here limitations are understood by Manor as hostile media landscapes, limited diplomatic representation, and a lack of bilateral ties. The chapter is connected with the previous one and suggests that these limitations are the true reason why diplomats fail to communicate with digital publics. Due to these barriers, diplomats are forced to create such digital technologies that condense time and space. As a satisfying example of these activities the author presents analyses of four virtual embassies established by the US, Israel, Palestine and Sweden. 
The eighth chapter is probably the only problematic one. The author introduces here the concept of "selfie" diplomacy, where the word "selfie" is a synonym for self-portrait or image of a nation. Manor defines this concept as an MFA's use of social media channels to create a nation self-portrait or brand; it is a form of national branding conducted via digital platforms. Doubts may arise as the term "selfie diplomacy" has already been used in the field to denote a different concept, not mentioned in this chapter. To illustrate the difference, the best example of the older application of the phrase would be selfie diplomacy conducted by Prime Minister Modi, which focuses on taking self-portrait digital pictures and posting them online. Most of the pictures come from the leaders' summits or bilateral meetings and promote mutual relations. Despite the chapter's interesting and convincing case studies (America's selfie in the age of President Trump and Poland's attempt to recreate its historical selfie), it may cause unnecessary conceptual disorder.

The ninth chapter is devoted to the role of ambassadors in the digitalization of public diplomacy. It argues that even though many high-rank diplomatic officials are so-called digital immigrants (born before 1980), they adopted and integrated digital technologies into their daily routine. Following the argument that ambassadors may use social media towards different ends, Manor analyzes the activities of three of them. The activities of Karen Pierce, the UK's Permanent Representative to the UN, are focused on the "behind the scenes" posts and providing the digital publics with real-time access to the world of diplomacy. On the other hand, the EU's ambassador to the US David O'Sullivan uses social media for gathering, curating, sharing and spreading selected news. On his twitter account, there are posts titled “Today's Must Read” or “Today's Must Watch". Lastly, the French ambassador Gerard Arnaud is presented as a branding genius as he easily attracts attention of US leaders.

The last chapter summarizes the book by underlining the main findings and returning to the three essential goals that have been attained, and presents the new avenues for research on public diplomacy.

The book offers not only a wide range of case studies from around the world but also a great theoretical foundation for future research. A variety of bibliographical citations show the comprehensive research that went into the writing.Different research methods applied in the book make it interesting and diverse, not only for scholars interested in the field but also for random readers. The book by Ilan Manor can be recommended to university professors and their students as the language is accessible and modern, the well selected case studies appear in almost every chapter and the theoretical background is thoroughly explained. To support his argumentation, Manor has included a range of figures illustrating the activities of diplomatic officials, graphs summarizing his own research and tables demonstrating the collected data, which gives additional value to the text. It can be said that the book's purpose has been achieved, research questions have been fully answered and the directions of further research have been properly set. 